\title{
UN TEXTO DA FRANXA ORIENTAL NO TOMBO DAS VIÑAS DE RIBADAVIA
}

\author{
Luz Méndez
}

Asociación Galega de Onomástica

\section{O TOMBO DAS VIX̃ S DE RIBADAVIA}

O texto do que vou falar forma parte do coñecido co nome de Tombo das viñas de Ribadavia, un pergamiño en romance que pertence aos documentos do Arquivo da catedral de Ourense e procede do mosteiro de Melón ${ }^{1}$. Está ben documentado: cítase, por exemplo, no Tombo de 1611 dese mosteiro que está no Arquivo Histórico Provincial de Ourense, no apartado de "Clero de Melón". Dise textualmente:

Ay un apeo o aberiguación de todas las casas uiñas y heredades que este Monasterio, el de Osera, Sant Clodio, Cela Noua y otros monasterios y señores tenían al tiempo en Riuadauia; echo por mandado del Rey don Alonso y es muy antiguo, sin fecha ni autoridad, escripto por una parte y otra en un pergamino largo por donde consta que este monasterio tenía en Riuadauia dos haceñas y que hauía casas en el lugar de Orjaas y otras muchas casas y uiñas que se le han perdido en Riuadauia y su término. Está ansimismo apeo de las casas, uiñas y heredades que este monasterio tenía entonces en Santisteuan de Nóboa que bien mirado eran más de la mitad de las casas del dicho lugar y las heredades y uiñas eran muchas. Están en el cajón de Riuadauia, legajo 14, númº 1 (f. 78 v).

Tamén está recollido noutro tombo deste mosteiro a onde o texto se traslada en 1800. É o pergamiño 6174 do Catálogo de Leirós (1951: 544-545)². Cambón Suárez (1957) recólleo na súa tese inédita sobre o mosteiro de Santa María de Melón e Olga Gallego (1986: 157-176) fai unha transcrición do texto cun breve comentario histórico. Ademais, este parece ser o documento

1. Ao longo do texto vaise subliñando o nome do mosteiro, posiblemente para unha fácil localización de cales eran as súas pertenzas e dereitos na vila de Ribadavia.

2. O autor dáo como documento de orixe descoñecida. 


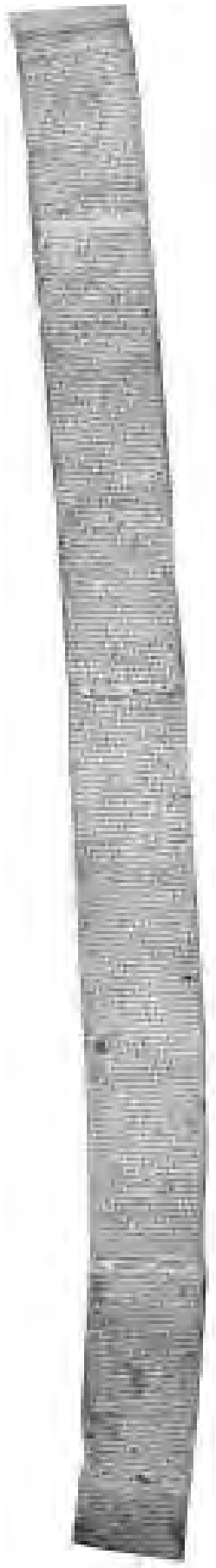

Fig. 1. Recto do Tombo das Viñas de Ribadavia

mencionado por Ferro Couselo (1957) nun artigo publicado en Vida Gallega en 1957. Hai que facer constar, non obstante, que tanto Leirós coma Olga Gallego, que transcribe parcialmente o pergamiño, ou Ferro Couselo, que comenta algúns datos do documento, só fan mención ao contido do recto, non sei se porque o verso o consideran unha continuación ou se porque para eles carece de interese. Só Olga Gallego fai mención á particularidade da lingua en que está escrito.

O Tombo das viñas é un pergamiño enrolado, formado por catro anacos cosidos (nun caso con cordel e en dous con coiro). O pergamiño mide en total 2 metros, $18 \mathrm{~cm}$ de longo e uns $16 \mathrm{~cm}$ de ancho nas partes de máis dimensión. O primeiro anaco é o máis pequeno $(20,5$ por $16 \mathrm{~cm}$. na parte de maior medida), engadiuse posteriormente e é o que está cosido con cordel. Non hai pegadas que dean certeza de que houbese máis anacos engadidos aínda que, polo fondo do recto, o texto está incompleto. Tampouco se pode asegurar que nalgún momento o cortasen porque, aínda que o fondo é irregular, non hai restos de tinta na parte máis longa e si parece haber espazo para que, se houbese outra liña escrita a seguir, se notase. É posible que continuase polo verso pero a observación do coiro con luz negra non deixa ver restos de escritura borrada.

No pergamiño débense considerar tres textos independentes que corresponden a distintas épocas. O primeiro, o escrito polo lado da carne, é o máis antigo, o que lle dá nome ao documento e no que nos imos centrar polas súas características lingüísticas excepcionais 
(texto A). O segundo é o escrito no verso do coiro e consiste nun texto pouco coherente, ás veces repetitivo e escrito por varias mans (texto B). Finalmente, o terceiro texto, correspondente ao recto do anaco máis pequeno de pergamiño; está borrado e só se pode ler coas técnicas adecuadas (texto C). O verso deste anaco utilizouse para poñerlle título ao documento. O feito de que este anaco estea cosido ao resto con cordel e o tipo de letra visible polo verso, máis moderna, evidencian que a operación de lle poñer título ao chamado Tombo das viñas se fixo moi posteriormente á escritura do recto ou do verso e, como non, do texto borrado.

O contido do texto borrado fai referencia ao aforamento dunha viña do mosteiro de Santa María de Melón.

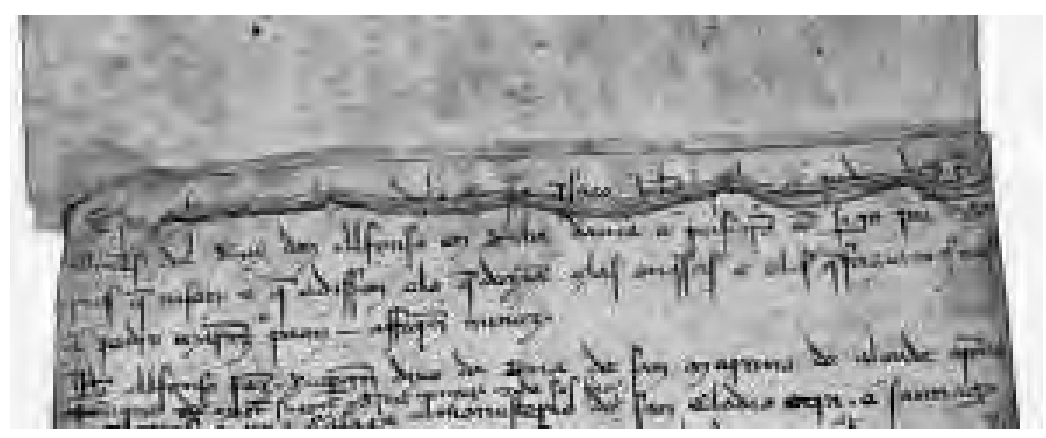

Fig. 2. Detalle do anaco inicial do recto pergamiño, cosido con cordel.

O texto que contiña está borrado.

No recto do documento utilízase tinta ocre, a letra é minúscula diplomática e non se manteñen marxes. A lectura é doada pero o pergamiño está roto en dous lugares polo lado esquerdo, o que afecta á lectura do principio de dous pares de liñas. A tinta está esvaída nalgúns lugares. O verso está escrito en gótica cursiva. Tampouco se manteñen as marxes e hai varias mans.

En canto ao contido, o texto A (que é o que imos comentar) é un rascuño, un borrador que recolle, basicamente, unha relación das posesións que teñen as ordes relixiosas en Ribadavia.

O texto B, o do verso do pergamiño, recolle as viñas, casas, soutos, foros e herdades do mosteiro de Santa María de Melón en Santo Estevo de Nóvoa (hoxe parroquia de Carballeda de Avia). 


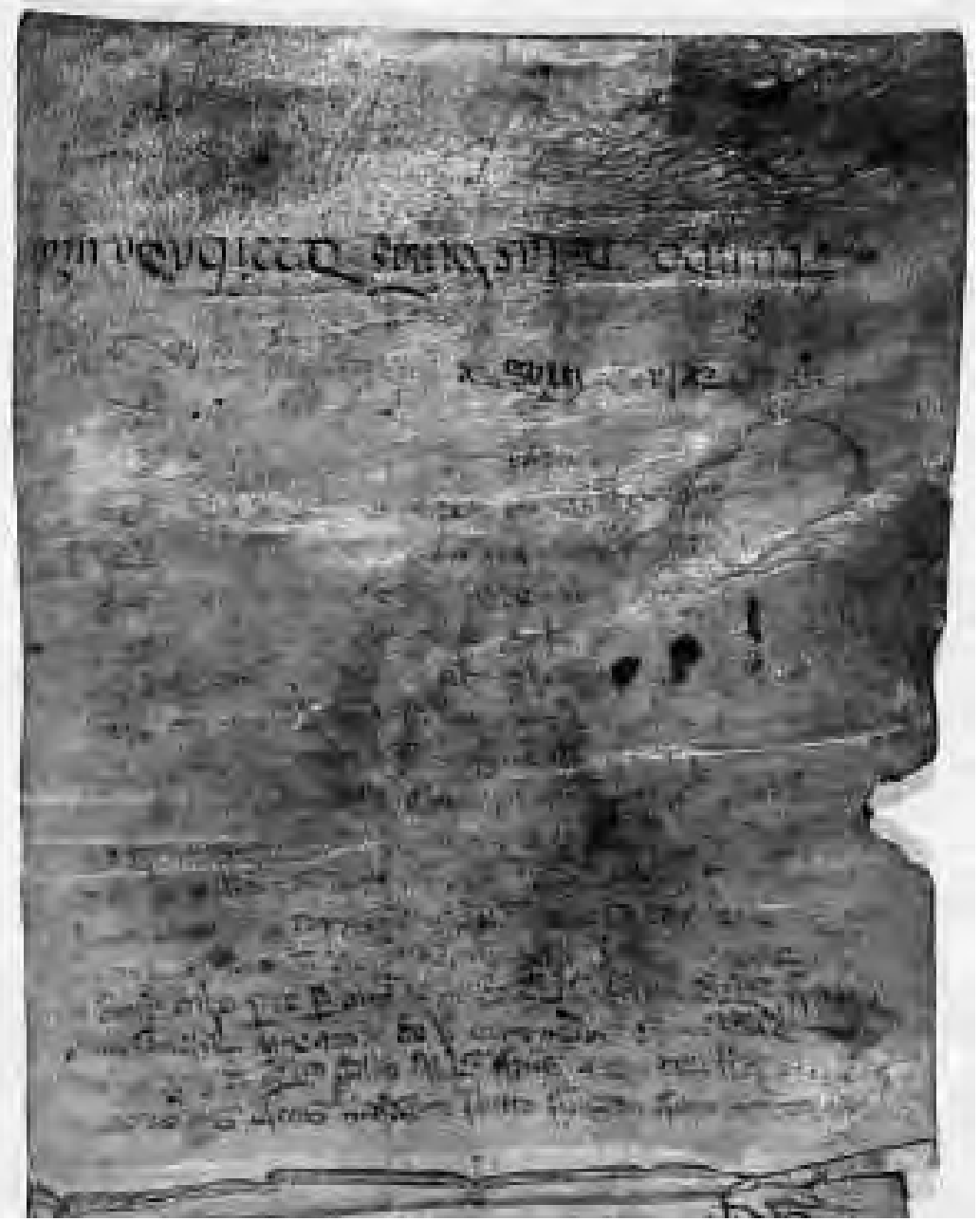

Fig. 3. Anaco inicial do pergamiño polo verso.

\section{PROBLEMAS DE DATACIÓN}

Aínda que Ferro Couselo, Cambón e Olga Gallego o datan en época de Afonso IX (Ferro Couselo propón 1228), de entrada, non parece doado determinar a data de ningunha das partes do documento. Fóra do texto borrado no palimpsesto, que aínda non analizamos en profundidade, nin no recto nin no verso hai cláusulas de datación, polo que teremos que basearnos noutros elementos. 
En relación ao verso do pergamiño (texto B), polo tipo de letra, gótica cursiva, e pola mención á "morteidade" (que xeralmente se refire á peste negra de 1348), podemos asegurar que non é anterior á segunda metade do século XIV.

Pero no texto que queremos comentar (texto A), non se menciona ningunha persoa nin hai algún dato que, en principio, nos permita situar o texto nun período temporal concreto: non hai nomes de bispos nin de abades e o nome do rei, Alfonso, non aparece con ningunha outra indicación.

Desde o punto de vista paleográfico, o tipo de letra, minúscula diplomática como dixemos, non parece solucionar gran cousa. Este tipo de escritura empeza a transformarse a mediados do século xIII e esa transformación vai levar á aparición da gótica cursiva, que se desenvolve plenamente na segunda metade desta centuria. Así e todo, a minúscula diplomática continúa usándose na documentación expedida polas chancelerías de Afonso X, Sancho IV, Fernando IV e Afonso IX, isto é, ata a metade do século seguinte (Millares Carlo 1975: 35-36). Outros trazos, coma a ausencia de $c$, que empeza a xurdir a principios do s. xIII ou o uso de $v$ en vez de $u$, cando equivale a consoante, que se inicia a mediados deste mesmo século xiII (García Villalada 1974: 293-295), tampouco axudan a aclarar as cousas.

A opción que nos queda, polo tanto, é intentar datar o texto en función do seu contido e dalgunhas personaxes ás que fai referencia, isto é, por un lado ver cál é a Ribadavia que se nos describe e tratar situar a vila nun momento da súa historia e, por outro, intentar identificar as persoas noutros documentos da zona e os seus arredores, para conseguir ter unha aproximación temporal.

A historia medieval do Coto do Burgo, como tamén se denomina a vila no texto, é fecunda e está bastante ben documentada. Ribadavia estivo desde principios da baixa Idade Media ligada á realeza e foi foco de interese de nobres e eclesiásticos por ser centro económico dunha zona aínda hoxe en día rica grazas á viticultura: o Ribeiro.

Fernando II concédelle o Foro a Ribadavia en 1164, pero o nacemento da vila pódese remontar a uns anos antes. Ferro Couselo (1957), no artigo mencionado, e, segundo cremos, seguindo os datos que nos proporciona o texto que imos comentar, establece que a vila naceu por presuria ${ }^{3}$ en tempos de Afonso VII e lígaa tamén á época de nacemento do mosteiro de Oseira, fundado por este rei en 1137.

Ribadavia pertenceu á diocese de Oviedo ata 1150. Pasou logo á de Ourense e posteriormente, desde 1213, quedou baixo a xurisdición eclesiástica de Tui.

3. Reivindicación ou reconquista polas armas. 
Os conflitos sobre a xurisdición eclesiástica e a cobranza dos décimos en Ribadavia foron frecuentes durante os últimos anos do século XII e os primeiros do XIII e foron parellos á aparición de mosteiros, catedrais e igrexas con intereses na vila (Romaní Martínez 1988: 107-127).

No documento menciónanse seis igrexas ligadas á vila: a de Castrelo, a de Santa María, a de Santiago do Burgo, a de Santo Estevo, a de San Xes e o Espital de San Xoán.

A igrexa de Castrelo ha de ser a igrexa da parroquia de Castrelo de Miño, no concello do mesmo nome. Esta parroquia linda coa de Ribadavia. A igrexa está xa documentada en 1167 (Eiján Lorenzo 1981: 64).

A igrexa de Santa María (Santa María da Oliveira ou do Burgo, noutros documentos) aparece xa mencionada en 1170.

A igrexa de Santo Estevo (Santo Esteuan no texto) debe facer referencia á da parroquia de Santo Estevo de Nóvoa, hoxe no concello veciño de Carballeda de Avia, pero que nun tempo foi de Ribadavia (Cf. Madoz). Xa está documentada no século XII (Eiján Lorenzo 1981: 126).

A igrexa de San Genés, así se denomina no texto (hoxe Santa María Magdalena), tamén está considerada como unha das máis antigas da vila. Xa está mencionada nos preitos monacais de finais do século XII e en xaneiro de 1213 o bispado de Tui consegue os décimos sobre ela nun acto de concordia con Oseira (Romaní Martínez 1988: 107-127). No noso documento xa pertence a Tui, polo que podemos afirmar que o documento é posterior a 1213.

A data de nacemento da igrexa de Santiago (tamén Santiago del Burgo no texto) é difícil de determinar, segundo os historiadores. Samuel Eiján Lorenzo (1981: 133 e ss.), estudoso da historia de Ribadavia, concorda con Murguía en que se debe establecer no primeiro terzo do século XIII, posteriormente a 1213, segundo Eiján, pois non aparece citada no acto de concordia entre Oseira e Tui dese ano.

A orde dos Hospitalarios de San Xoán (o Espital, no noso texto) estaba xa establecida na vila antes de 1213 (Eiján Lorenzo 1981: 118, Romaní 1988: 113).

Se damos por bo estes datos, podemos levar a datación deste documento a unha época posterior a 1213.

Non se menciona no texto, non obstante, a igrexa de Valparaíso (hoxe do Portal), asociada ao nacemento do convento de San Domingos. Sábese que o documento de acta de colocación da primeira pedra da igrexa deste mosteiro, por parte do bispo de Tui Egidius (1250-1273) ${ }^{4}$, está datado en 1271. Parece difícil imaxinar que se a igrexa ou o mosteiro xa existisen na época de redacción do documento non estivesen citadas.

4. http://www.diocesetuivigo.org/Nosadiocese/episco.htm (última consulta: 2-5-2006) 
Temos así pois un período amplo de 58 anos para datar o documento, entre 1213 e 1271.

Das persoas mencionadas neste texto A pouca información se puido obter. En primeiro lugar cítase o rei don Alfonso. Este rei pode ser Afonso IX de León (VIII de Galicia) ou Afonso X. No caso de ser o primeiro, o texto estaría datado entre os anos 1213 e 1230 e sería outro dos exemplos de uso do romance durante o reinado deste rei. Se o mencionado é Afonso X, o uso do romance xa é esperado e daquela a datación pódese delimitar entre 1252 e 1271. Cítanse tamén o arcebispo de Santiago e o bispo e Ourense pero non se di o seu nome.

Olga Gallego (1986: 160-161) quere identificar varias das persoas que aparecen mencionadas, a partir da documentación relativa a Afonso IX recollida por Julio González (1944): dona Teresa, "que pudiera ser la amante del rey, Teresa Gilı; dona Steuaína "pudiera hacer referencia a D. ${ }^{a}$ Estefanía Pérez, amante también del rey"; don Rrichardo "podría ser el que compró a Pedro Midiz una viña en Ribadavia" en 1228; don Galter "es quizás el maestro que hizo los puentes de Gradefes y de Carrión... según consta en documento... del año 1202"; Pedro Dente "pudiera ser el padre de un Bartolomé que falsificó moneda...”; Mayor Pérez «es quizás la señora del mismo nombre que con su esposo Alfonso Pérez donan al monasterio de Osera en 1206 ciertos bienes".

Á parte das hipóteses de Olga Gallego, que non cremos suficientemente avaladas, escollemos uns cantos nomes que nos pareceron significativos e buscámolos na documentación da época máis próxima no espazo. Encontrámolos mencionados en varios textos das coleccións documentais do mosteiro de Oseira (CDOseira), a catedral de Ourense (DocCOu) e o mosteiro de San Domingos de Ribadavia (CDRibadavia):

1. Pedro Tacón [“Petro Tacón, DocCOu, n49, ano 1212, p. 63].

2. Pay Ranado ["Pelagii dictus Raniadus, CDOseira, n210, ano 1220, p. 208] Funciona xa "o Souto de Pay Ranado" como topónimo. Vid. TMILG.

3. Pedro Martiz Paan ["Petrus Martini dictus Paian en CDOseira, n245, ano 1224, p.243 e Petri Martini Payán CDOseira, n383, ano 1234, p. 368 e n384, 1235, p. 368].

4. Fernandino ["Fernandino", CDOseira, n341, 1231, p.330-331].

5. Domingo Caluo ["Dominico Calvo", CdOseira, n341, 1231, p.330-331].

6. Don Galter ["domno Galter", CDOseira, n350, ano 1232].

7. Johán Gibelas ["Iohanne Gibelas", CDOseira, n371, ano 1233, p. 356].

8. Johán Pérez de Castrelo [Iohannes Petri de Castrello", CDOseira, n401, ano 1235, p.382]. 
9. Martín Saluadores ["Martinus Salvadoriz", DocCOu, n 145 e 185, 1233 e 1235 , p.139 e 147.

10. Johán Gardelas ["Gardelas", CDOseira, n399, 1235, p. 382; ou "Iohanis Petri Gardelas" tamén en CDOseira, n469, 1240, p.439].

11. Pay Marauilla [Petro Pelagii Maravilla”, CDOseira, n469, ano 1240, p. 439 ou "Pelagio Maravilla", CDOseira, n489, ano 1241, p.460].

12. Lourentio Páez ["Laurencio Pelagii”, CDOseira, n469, ano 1240, p. 439].

13. Pedro Dente [Petri Dentis", CDOseira, n541, ano 1244, p. 507 ou "Petrus Fernandi, laycus de Burgo Ripe Avie dictus Dente", CDOseira, 249, ano 1224, p. 246].

14. Joán Páez Santiagués ["Pelagii dictus Santiagues”, CDOseira, n689, ano 1252, p. 649 ou "Johannes Pelagij Jacobitanus", CDRibadavia, n1, ano 1271, p.63].

15. Johán Pérez Gibarro ["Joannes predictus Gibarrus", CDRibadavia, n1, ano 1271, p. 63].

16. Rruy Pérez ["Rodricus Petri, mils. de Burgo", CDRibadavia, n1, ano 1271, p. 63].

17. Rruy Suárez ["Rodricus Sugerij”, CDRibadavia, n1, ano 1271, p. 63].

18. Johán Martiz ["Joannes Martinij", CDRibadavia, n1, ano 1271, p. 63].

19. Martín Monago ["Martinus Moogo", CDRibadavia, n1, ano 1271 p. 63].

20. Fernán Núnez ["Fernandus Nuni”, CDRibadavia, n1, ano 1271 p. 63].

21. Fernán Pérez ["Fernandus Petri de Campo", CDRibadavia, n1, ano 1271, p. 63].

22. Martín Monago ["Martinus Moogo", CDRibadavia, n1, ano 1271, p.63].

23. Martín de las oueyas ["Petrus Martini Ovella", CDOseira, n1056, 1274, p. 1005.

Se estas persoas son as mesmas que se citan no documento, seguímonos movendo nun período de arredor de 50 anos que non nos axuda moito. Así e todo, temos que destacar o caso do documento da fundación da igrexa do mosteiro de San Domingos de Ribadavia. Nel hai 9 persoas con nomes coincidentes coas do noso texto, aínda que algúns sexan nomes bastante frecuentes (vid. núms. 15 a 23). Tamén poderiamos aínda considerar que o bispo de Tui, dominus Egidius, fose o don Eio que se menciona no recto do Tombo das viñas. Iso aclararía moito as cousas pero, basearnos na simple aparición do nome Eio sen outra referencia, parécenos tan arriscado como admitir as hipóteses de Olga Gallego. Primeiro porque Eio (<EGILO) é nome feminino (Boullón Agrelo 1999: 193), aínda que aquí se acompaña de don. Segundo porque o nome EGILIUs só aparece documentado coas formas Egidius ou Egidio (Boullón Agrelo 1999: 193). E terceiro porque, aínda que deamos por feito que o autor do texto confundiu os nomes, nunca poderemos asegurar que a persoa referida sexa o bispo de Tui. 
En resumo, dos datos onomásticos resumidos atrás podemos establecer o seguinte cadro cronolóxico

\begin{tabular}{l|c|c|c|c|c|c|c}
\hline Década & 10 & 20 & 30 & 40 & 50 & 60 & 70 \\
\hline N. ${ }^{\circ}$ Persoas & 1 & 3 & 8 & 5 & 1 & & 11 \\
\hline
\end{tabular}

Habería aínda que analizar máis pormenorizadamente no texto aquelas persoas das que se di que foron algunhas propiedades e aquelas persoas que teñen aínda propiedades, ou o que é o mesmo, as probables persoas vivas no momento da redacción do texto e aquelas que tamén é probable que estean mortas. Tal vez se podería así delimitar un pouco máis a época en que se escribiu.

Ferro Couselo considera como suposta data do documento que cremos este 1228 pero non deixa dito qué feito o leva a facer iso. É posible que se guiase para establecer a data por algunha das visitas de Afonso IX a Ribadavia ou arredores, todas bastante ben documentadas (J. González: 1944)

Con todo e vistos estes datos, non podemos deixar de ter en conta a hipótese de que o texto corresponda á segunda metade do século XIII e ao reinado de Afonso X.

A análise lingüística do recto deste documento quizais nos poida achegar algún dato máis no proceso de datación e, a seguir, sinalamos algunhas das características máis significativas.

E é, com se verá, un novo exemplo de galego oriental (ou leonés occidental segundo outros autores) na nosa primeira documentación romance.

\section{CARACTERÍSTICAS LINGÜÍSTICAS DO TEXTO}

\subsection{Grafemas}

Utilízanse 23 grafemas para representar os sons vocálicos e consonánticos do texto.

Para o fonema vocálico /i/ altérnase o uso dos grafemas $<\mathrm{i}\rangle,\langle\mathrm{j}\rangle$ e $\langle\mathrm{y}\rangle$ (este último sempre como segunda parte dun ditongo: cónjgos; Menendj; Nunj / Osseyra; máys; rrey; Pay; ye; yeran). Para representar o fonema /u/ tamén se usa en ocasións $v$ pero só en posición inicial (Vclés;Vcrés; vna).

O grafema $<\mathrm{c}>$ utilízase tanto para a oclusiva, velar, xorda $/ \mathrm{k} /+a, o, u$ : $c a$ sa; coma para a sibilante, predorsodental, xorda/ts/: cerca, Cellanoua.

O dígrafo <ch $>$ representa xeralmente o fonema africado postalveolar $/ \mathrm{t} \mathrm{f}$, pero nun caso aparece representando o oclusivo, velar, xordo /k/.

Só hai un caso de consoante xeminada e non é etimolóxico: Ffernán. 
A grafía $<\mathrm{g}>$ utilízase tanto para a oclusiva velar sonora $/ \mathrm{g} /$ ante as vocais $a, o, u$ (aínda que tamén hai algún caso con $e$ : Domíngez) coma para a fricativa, postalvolar, sonora /3/ ante $e, i$ (Genés) e ante $a$ nun caso (Orgaes).

A alveolar lateral está representada polos grafemas $<\mathrm{l}>$ e $<1 \mathrm{ll}$ : Castrello, Celanoua, uilla, uila.

O grafema $<$ n $>$ representa tanto o fonema nasal alveolar coma o palatal, aínda que este último tamén aparece, en ocasións, representado por <ni $>$ : azenias, quiniones. $\mathrm{O}<\mathrm{n}>$ aparece frecuentemente abreviado cun trazo sobre a palabra.

As grafías $<\mathrm{s}>\mathrm{e}<\mathrm{ss}>$ representan respectivamente a fricativa alveolar sonora e a xorda aínda que hai algunha confusión.: casa, ese, esse, odissen, Osseyra.

A grafía $<\mathrm{u}>$ representa a bilabial, fricativa sonora e a labiodental: caualeiros, Caruonero, uina, Steuan. A grafía $<_{\mathrm{V}}>$, menos frecuente, só a bilabial:, vina.

$\mathrm{O}<\mathrm{x}>$ utilízase para a fricativa, postalveolar, xorda: dixo, exido, e nun exemplo aparece como grafía latinizante: sex.

$\mathrm{O}<\mathrm{y}>$ parece ser a única grafía para a lateral palatal (se esa era a pronuncia ${ }^{5}$ ): fiyo, Oueyas, a non ser que se puidese chegar a determinar algún caso de $<\mathrm{l}>$ e $<1 \mathrm{l}>$ con ese valor: villa, aínda que tamén Castrello, Cellanoua, Compostellano.

O grafema $<\mathrm{z}>$ utilízase para representar a sibilante predorsodental sonora e, nalgún caso tamén a xorda: deziamos, faziamos / plaza. En tres casos da mesma palabra (iaz) obsérvase a transformación nunha especie de $<5>$, frecuente xa nos documentos galegos do século XIV.

\subsection{Vocalismo}

As vocais breves tónicas latinas vacilan entre a ditongación e a forma monotongada.

\subsection{1. $\breve{\mathrm{E}}$ latino.}

Vacílase entre o resultado $<$ e $>$ e a ditongación $<\mathrm{ie}>(<\mathrm{ia}>)$ :

\begin{tabular}{|l|l|l|}
\hline \multicolumn{1}{|c|}{$\breve{\mathbf{E}}>\mathbf{e}$} & \multicolumn{1}{c|}{$\breve{\mathbf{E}}>\mathbf{i e}$} & \multicolumn{1}{|c|}{$>\mathbf{i a}$} \\
\hline ten; ten; tenen; tenla; & pusieron; dieron; tien; & diaz (dez) \\
tenna; tendas; Serra; & tiene; tienna; fizieron; & \\
Ferro; Dente; & nyetos; Miguiel; mugier; & \\
comenzamento; & ye; yeran & \\
finamento & & \\
\hline
\end{tabular}

5. García Arias (1995: 631) 


\subsection{2. Ŏ latino.}

Vacílase entre o resultado $<\mathrm{O}>$ e a ditongación $<$ ue $>(<$ oe $>)$ :

\begin{tabular}{|l|l|l|}
\hline \multicolumn{1}{|c|}{$\breve{\text { o }>\text { o }}$} & \multicolumn{1}{c|}{ ó > ue } & \multicolumn{1}{c|}{ oe } \\
\hline bona; bonas; foron; & buenos; muerte; ueocho & boenas \\
furon; morte; ortas; & (oito); fueron & \\
ponte; ponte; porto; & & \\
soldos; soldu; ssoldo; & & \\
ssoldos; ssoldos & & \\
\hline
\end{tabular}

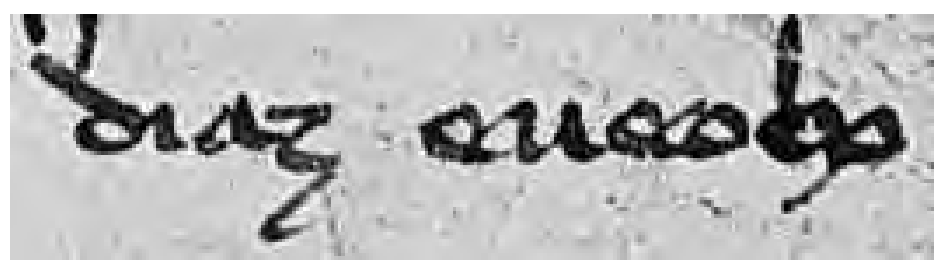

Fig. 4. Detalle da palabra diaz e ueocho (dezaoito) cos resultados de $\breve{\mathbf{~}}$ e $\breve{\mathbf{o}}$.

3.2.3. Nos ditongos decrecentes primarios ou secundarios tamén se vacila entre o mantemento ou a monotongación:

3.2.4. AI primario > - ei /-e: Mantega < MANTAICA; Uega, Ueyga $<$ *IBAIKA

3.2.5. ai secundario > -e: queso < CASEUM

3.2.6. No sufixo -ARIUm tamén se dá a vacilación entre -eiro / -ero. O mesmo sucede no feminino.

-EIRO: caualeiros; Ceboleiro; Criueiro; dineiros; Ferreiro; oleyro; Oteiro; pelteiro.

-ERO: reguero; carpentero; Caruonero; Castenero; Cebolero; correro; foreros; Palumbero; pelitero; primero.

-EIRA: carreira; leira; leiras; Oliueira; Pedreira; pescadeiras; leyra; leyras; Osseyra.

-ERA: carrera; fazendera; Lauandera; lera; leras; Noguera; Ossera; pereras.

3.2.7. Noutros casos de ditongo - ei- secundario (derecho; directuras; exido; lexauan) só aparecen casos de monotongación, aínda que no segundo exemplo podemos dubidar entre entender que hai unha grafía latinizante ou unha nova opción gráfica á hora de representa-lo ditongo. 
3.2.8. Unha situación similar dáse no caso do ditongo latino -Au. No ditongo primario temos un exemplo de mantemento co resultado ou: couto; pero tamén varios caos de monotongación: odissen; odiran; odiron; otorgó. No caso do ditongo secundario únicamente temos exemplos de monotongación: Oteiro; otra; otras; otro; otros; soto; sotos.

\subsection{Consonantismo}

\subsubsection{Consoante $n$}

Interpretei sempre o trazo sobre a palabra como abreviatura dun $n$ e nunca como trazo de nasalidade. Non hai ningún caso de -N- que se represente con til. O $n$ só aparece abreviado en posición final de sílaba ou palabra.

$\mathrm{O}$-N- intervocálico adoita manterse: boenas; bona; bonas; buenos; conóligos; Esteuan; Genés; Menéndiz; Menendj; Monago; monasterio; monesterio; Órdenes; padrones; Quinzana; senara; Steuan; tener; Yano. Aparecen non obstante algúns exemplos de perda, xeralmente en nomes propios: cónjgos; Martiz; Moogo; Steuaína.

O resultado de -NJ- e do sufixo -INUs sempre se representa coa grafía $<$ n $>$. ao ser esa a grafía para a nasal palatal -como demostran as palabras que coinciden nos seus resultados en galego, castelán e leonés, p. ex. viña-, dificúltase a interpretación da fonética doutras palabras: ano, dona.

\subsubsection{Consoante $l$}

Coma no caso do -N-, o -L- intervocálico adoita manterse: molinos; $\mathrm{Pa}$ lumbal; Palumbero; Peláez; rengalengas; rrengalengos; rregalengas; solares; quales. Hai, non obstante, casos de perda, nesta ocasión, sempre en nomes propios: Páez; Orgaes; Pay; Saa.

$\mathrm{O}$-LL- xeminado represéntase indistintamente con un $l$ simple ou un xeminado. Con todo, cremos que se debe interpretar a xeminada como unha grafía latinizante: uila; caualeiros; Ceboleiro, Cebolero // uilla; villa; Castrello; Cellanoua; Uasallo.

No grupo -LJ- observamos varios resultados. Para a evolución dese grupo latino utilízase maioritariamente a grafía $<\mathrm{y}>$ : fiyo; muyer; Oueyas; yes < ILLES, pero tamén aparece $<\mathrm{gi}>,<\mathrm{l}>$ e a latinizante $<\mathrm{li}>$ : mugier / Marauila / Mergulión. O grupo tamén se perde en ocasións, en concreto, no caso da palabra "fillo": fio; fios; fýos.

3.3.3. Grupos consonánticos (-K'L-, $\mathrm{PL}_{-}^{-}, \mathrm{CL}_{-},-\mathrm{CT}^{-}, \mathrm{C}^{\mathrm{e}, \mathrm{i}},-\mathrm{TJ}-,-\mathrm{cons}+{ }^{+\mathrm{TJ}-} \mathrm{e}$ $\left.-\mathrm{RC}+{ }^{\mathrm{e}, \mathrm{i}}\right)$

Do grupo intervocálico -K’L- só temos un exemplo que, coma no caso anterior, tamén aparece grafado co $<\mathrm{y}>$ : Oueyas. 
O grupo PL-, aínda que só temos un exemplo, presenta unha grafía semellante á dos grupos anteriores: Yano.

Pola contra, para o grupo CL-, tamén cun único exemplo, utilízase a grafía $<\mathrm{x}>$ : xaman.

Os grupos latinos -CT- e -CTJ- aparecen desenvolvidos na grafía $<\mathrm{ch}>$ : $\mathrm{sO}$ bredichas; Sancha; Saln]chia; Sánchez; pero hai tamén un exemplo en que o grupo -CT- se mantén (directuras). Isto pódese interpretar como un latinismo ou como a dificultade da representación do ditongo $<e i>$, dificultade reflectida frecuentemente nos primeiros documentos en romance.

O grupo $\mathrm{C}^{+}{ }^{\mathrm{e}, \mathrm{i}}$ - inicial aparece sempre representado por $\langle\mathrm{c}\rangle$ : cerca; o mesmo grupo en posición intervocálica, cando queda en posición final por perda da vocal, gráfase sempre con $<\mathrm{z}\rangle$.

O grupo -TJ- ofrece o resultado gráfico $<\mathrm{z}>$ : plaza. O grupo -cons.+TJ alterna nos seus resultados varias grafías: $\langle\mathrm{z}>$ : comenzamento, Lorenzo, Lourenzo, Quinzana; o latinismo <ti $>$ : Lourentio; e $<\mathrm{ci}>$ : renembrancia, pitancia. Esta última solución, <ci>, é tamén a utilizada para o grupo $-\mathrm{RC}^{\mathrm{e}, \mathrm{i}}$ : tercia

\subsection{Morfoloxía}

\subsubsection{Artigo definido}

No masculino vacílase no uso entre (e)lo [12 casos: elo (1); lo (1); elos (4); pelos (2); pelo (1); delos (1); delos (2) ] e el, aínda que el (22 casos + 43 de contracción coa preposición de) é bastante máis frecuente. Hai dous únicos casos de artigo masculino o (2) e un do feminino plural as (1), formas que tamén contraen coa preposición de: $d o^{6}(2), d a(7), d o s$ (1) e das (2). A forma máis frecuente no feminino singular é ela (83 casos entre singular e plural), aínda que tamén abunda la (25 casos).

No cadro a seguir deseñamos o paradigma e subliñamos a forma máis frecuente no texto:

\begin{tabular}{l|c|c|}
\cline { 2 - 3 } & Singular & Plural \\
\hline Masculino & elo $/ \underline{\text { el } / o} / \underline{\text { elos } / \underline{\text { los }}}$ \\
\hline Feminino & $\underline{\text { ela } / \text { la } / l / a}$ & $\underline{\text { elas } / \text { as } / \text { las }}$ \\
\hline
\end{tabular}

O artigo contrae coas preposicións de, en e per. Non temos ningún exemplo de contracción coa preposición con pero tampouco casos en que non contraia.

6. Nos dous casos forma parte dun apelido: María do Rrío e Joam do Olio. 
Na contracción coa preposición en, o resultado unánime é enno (6) / en$n a(s)$ (12), con casos de simplificación da consoante, ena (3). Na contracción coa preposición $a$, os resultados son ala (2), a la (3) alas (1), a lo (1), al (20), alos (1) a los (3)

No cadro a seguir deseñamos o paradigma e subliñamos as formas máis frecuentes. Débese facer notar que as formas xuntas ou separadas corresponden á literalidade do texto.

\begin{tabular}{|c|c|c|c|c|c|c|c|c|c|}
\hline & \multicolumn{2}{|c|}{ EN } & \multicolumn{2}{|c|}{ A } & \multicolumn{2}{|c|}{ DE } & \multicolumn{2}{|c|}{ PER } & $\mathrm{CON}$ \\
\hline & sing. & pl. & sing. & pl. & sing. & $\mathrm{pl}$. & sing. & $\mathrm{pl}$. & \\
\hline Masculino & enno, enno & $\varnothing$ & $\underline{a l}$, a lo & a los, alos & del / do & delos $/$ dos & pelo & pelos & $\varnothing$ \\
\hline Feminino & $\begin{array}{l}\text { ena, } \underline{e n n a} \text {. } \\
\text { enna }\end{array}$ & $\underline{e n n a s}$ & ala, a la & alas & dela /da & delas /das & pela & $\varnothing$ & $\varnothing$ \\
\hline
\end{tabular}

\subsubsection{Demostrativos}

A partir do texto, e como se observa no cadro, non se pode completar o paradigma dos demostrativos. Destaca a ausencia de formas neutras e a forma plural de estos, sen regularizar co masculino. Cando hai variantes, sublíñanse as formas máis frecuentes.

\begin{tabular}{l|l|l|l|l|l|l}
\cline { 2 - 7 } & \multicolumn{2}{c|}{} & \multicolumn{2}{c|}{ plural } \\
\cline { 2 - 7 } & singular & \multicolumn{1}{c|}{ plural } & singular & \multicolumn{1}{c}{ plural } & \multicolumn{2}{|c}{ singular } \\
\hline Masculino & este & estos & $\underline{\text { esse }}$, ese & $\varnothing$ & aquel & $\varnothing$ \\
\hline Feminino & esta, aquesta & estas & $\varnothing$ & $\varnothing$ & $\varnothing$ & $\varnothing$ \\
\hline Neutro & $\varnothing$ & $\varnothing$ & $\varnothing$ & $\varnothing$ & $\varnothing$ & $\varnothing$ \\
\hline
\end{tabular}

\subsubsection{Posesivos}

No texto só hai exemplos do paradigma da terceira persoa. O posesivo vai sempre anteposto ao substantivo e nunca o precede o artigo. Cando hai variantes, sublíñanse as formas máis frecuentes.

\begin{tabular}{l|l|l}
\cline { 2 - 3 } \multicolumn{1}{c|}{} & \multicolumn{1}{|c}{ Masculino } & \multicolumn{1}{c}{ Feminino } \\
\hline Singular & $\underline{\text { so }, \text { su }}$ & $\underline{\text { súa }, \text { su }}$ \\
\hline Plural & sos & súas \\
\hline
\end{tabular}

\subsubsection{Pronomes persoais tónicos e átonos}

Polo carácter descritivo do texto, só temos exemplos do paradigma de terceira persoa singular e plural. 
Serie tónica

\begin{tabular}{|c|c|c|c|}
\hline & Masculino & & Feminino \\
\hline $1^{a}$ persoa & \multicolumn{3}{|c|}{$\varnothing$} \\
\hline $2^{\mathrm{a}}$ persoa & \multicolumn{3}{|c|}{$\varnothing$} \\
\hline $3^{\mathrm{a}}$ persoa & $e l$ & & ela \\
\hline $4^{\mathrm{a}}$ persoa & \multicolumn{3}{|c|}{ nós } \\
\hline $5^{a}$ persoa & \multicolumn{3}{|c|}{$\varnothing$} \\
\hline $6^{a}$ persoa & eles & consigo & elas \\
\hline
\end{tabular}

Serie átona

\begin{tabular}{c|c|c|c|}
\cline { 2 - 4 } & refl & \multicolumn{2}{c|}{ non reflex. } \\
\hline & & Acusativo & Dativo \\
\hline $1^{a}$ persoa & $\varnothing$ & $\varnothing$ & $\varnothing$ \\
\hline $2^{a}$ persoa & $\varnothing$ & $\varnothing$ & $\varnothing$ \\
\hline $3^{a}$ persoa & $s e$ & $l o, l a, n a$ & $\varnothing$ \\
\hline $4^{a}$ persoa & $\varnothing$ & $\varnothing$ & $\varnothing$ \\
\hline $5^{a}$ persoa & $\varnothing$ & $\varnothing$ & $\varnothing$ \\
\hline $6^{a}$ persoa & $\varnothing$ & $\varnothing$ & $y e s$ \\
\hline
\end{tabular}

Os alomorfos do pronome átono de acusativo de terceira persoa, aparecen, enclíticos e unidos ao verbo, segundo as seguintes regras:

-lo: despois de -r (dixelo ýan). Hai tamén un caso de combinación co pronome reflexivo se (non se lo sabian)

-la: despois de vocal (ála a tener María Rodrígez por en sos días) ou de -n (tenla Fernán Eanes).

-na: despois de -n (tenna Arias Núnez; tienna Johán Núnez). Nótese que o $-n$ final do verbo vai nos dous casos abreviado.

\subsubsection{Verbo}

Entre as formas verbais que aparecen no texto merecen atención especialmente as formas con vocal $\breve{\mathrm{E}}$ ditongada: ye, yeran tien, tienen, dieron, fueron, pusieron, que alternan coas formas que non ditongan que son minoritarias. Tamén queremos chamar a atención sobre a perda do -e final na $3^{\mathrm{a}}$ persoa do presente dalgúns verbos da segunda conxugación: iaz, iatz, tien e na monotangación do ditongo nalgúns casos da $3^{\text {a }}$ persoa do perfecto dos verbos da primeira conxugación: otorgó, sacó (fronte a morou) ou a da forma fu. 
INDICATIVO

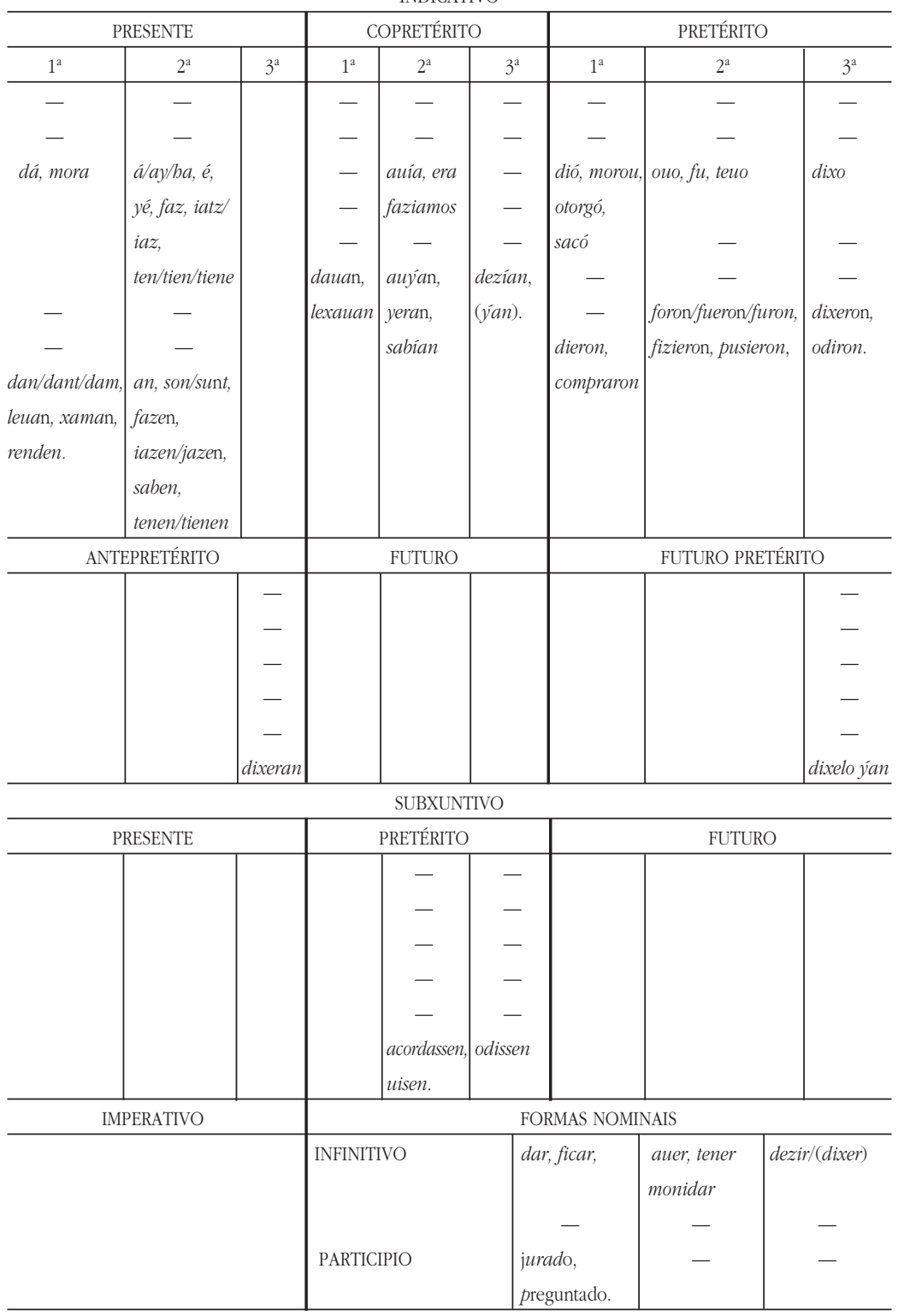




\section{CONCLUSIÓNS}

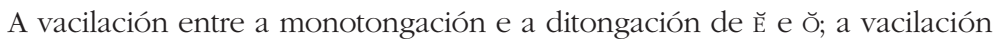
nos resultados de -AU e -AI primarios e no sufixo -ARIUM; a perda ou non de -N- e -L- son, entre outras, características que encadran o texto do recto do Tombo das Viñas de Ribadavia nunha serie de documentos da franxa oriental do galego, coma os Foros de Castelo Rodrigo ou algúns dos cartularios de Carracedo, Castañeda ou San Pedro de Montes (Lorenzo 2004b: 39-40), por exemplo. É nese contexto en que debemos estudar a lingua do texto.

\section{CODA}

Quero finalizar con dúas apreciacións sobre a lingua do texto en relación coas dificultades sobre a súa datación.

Entre os documentos do mosteiro de Melón transcritos por Cambón Suárez (1957) na súa tese de doutoramento hai outros dous documentos de características lingüísticas similares: un datado en Mayorga (na provincia de Valladolid en 1246) e outro en Palacios (posiblemente Palacios de Campos, Medina del Campo, Valladolid), en 1256 e signados respectivamente por don Yanes, notario do concello, e Johan Johannis, jurado do concello de León, probablemente a mesma persoa. ¿Puido ser tamén el quen redactase o noso texto?

Na documentación en leonés que consultei ata o momento encontrei varios documentos cunha fórmula de inicio semellante a do texto que estamos a comentar: (Esta ye la) renembrancia... Catro pertencen ao mosteiro de Carrizo (docs. 598, 599, 602 e 603) e non teñen data. Casado Lobato (1983), a editora, dátaos no século XIII. Os outros tres documentos están na colección documental da catedral de León, un datado entre setembro do ano 1271 e o 29 de marzo de 1972 (doc. 2317) e dous en xaneiro do ano 1272 (docs. 2312-2313). Estes sete documentos son rascuños, anotacións feitas sen gran coidado, posiblemente para logo volver ser redactados con fórmulas máis solemnes. Iso pode explicar no caso de Carrizo, coma no noso, a falta de data.

Outra vez, estas dúas últimas consideracións parecen levarnos máis cara á segunda metade do século XIII que cara á primeira a pesar da opinión que ata agora se veu tendo sobre a datación do Tombo das viñas. 